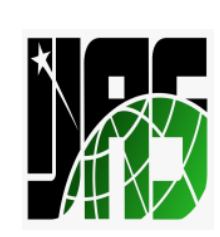

Indonesian Journal of Arabic Studies, Vol.3 Issue 1, May 2021 Avaliable online at:

http://www.syekhnurjati.ac.id/jurnal/index.php/ijas/index

DOI : 10.24235/ijas.v3i1.8055

Published by Departement of Arabic Language and Literature, Faculty of Adab, IAIN Syekh Nurjati Cirebon, Indonesia

\title{
The Contributions of Ibn Jinni in the Science of Arabic Prosody and Rhyme
}

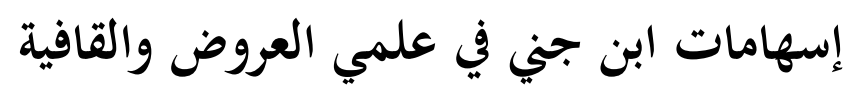

Mohamed Aziz Abdelmaksoud Sayed Ahmed

mohammadaziz1974@yahoo.com

Kulliyyah of Arabic Language

Sultan Abdul Halim Mu'adzam Shah International Islamic University, Malaysia

Ragab Ibrahim Ahmed Awad drragabibrahim@unishams.edu.my

Kulliyyah of Arabic Language

Sultan Abdul Halim Mu'adzam Shah International Islamic University, Malaysia

Elsayed Mohamed Salem Alawadi

sayedsalim@unisza.edu.my

Faculty of Languages and Communication

Sultan Zainal Abidin University, Malaysia

• Received: 01.03.2021 • Accepted: $30.04 .2021 \quad \bullet$ Published online: 05.05.2021

Abstract: This study highlights Ibn Jinni's contribution to Arabic poetry, especially in Arabic prosody (Al-'Arūd) and rhyme (Al-Qawafi) and to describe his approach to compiling in Arabic prosody and rhyme. This study is a qualitative research using descriptive and analytic methods. Description is useful for describing the life of Ibn Jinni and his knowledge, then his contribution to the science of Arabic prosody and rhyme, and analysis is carried out to analyze the formulation of his approach in Arabic poetry, namely prosody and rhyme. The study found that Ibn Jinni's Prosodi concept as stated in his work entitled Al-'Arud agrees with the principles put forward by AlKhalil bin Ahmed, especially in fifteen poetic meters (buhur) and differ in one meter (bahar). Ibn Jinni has a thematic method in making poetry works, this makes it very easy for students to understand learning the prosody of Arabic poetry and rhymes. 
Mohamed Aziz Abdelmaksoud Sayed Ahmed, Ragab Ibrahim Ahmed Awad, Elsayed Mohamed Salem Alawadi

Keywords: Arabic Poem, Ibn Jinni, Prosody, Rhyme, Efforts

الملخص: هذا بحث يلقي الضوء على جانب من جوانب إسهامات ابن جني في علم العربية، ألا وهو إسهامه في علمي العروض والقافية. ويهدف إلى توضيح ملامح منهج ابن جني في

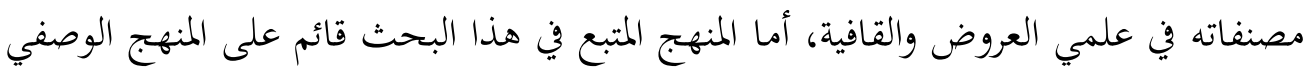
و التحليلي؛ حيث يصف حياة ابن جني، وآثاره، وما قدمه من إسهامات في علمي العروض

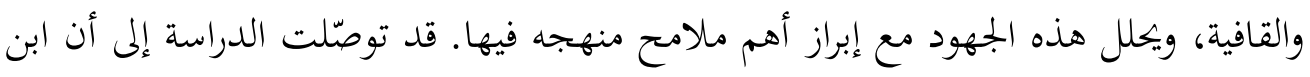

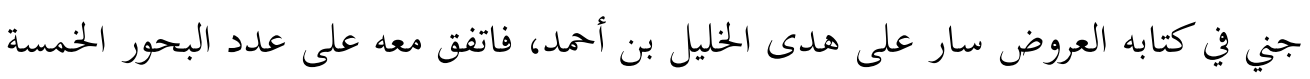

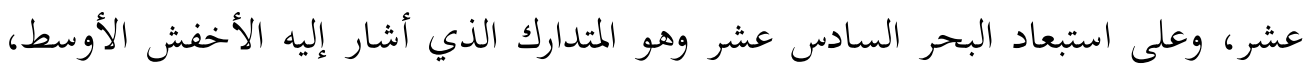

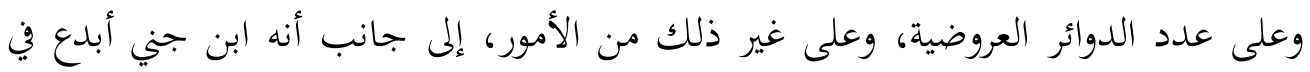
الكتابة العروضية المقطعية وهو نمط من الكتابة لم يلتزم به من سبقه، أو من عاصره، أو من جن جاء بعده، فهي طريقة موضوعية تُيَسّر كثيرا على الدارس فهم المكتوب وإنجازه. فقد كان ابن جني

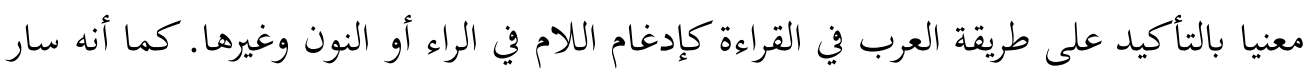
في مختصره في علم القافية على فج من سبقه. كلمات دلالية: العربية، ابن جني ، العروض، القافية، جهود

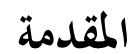

فإن اللغة العربية من أشرف اللغات وأعلاها مكانة فبها نزل القرآن الكريم الذي زاد من رفعتها وانتشارها في العالم الإسلامي وغير الإسلامي؛ حيث صارت لغة التواصل والحوار، ولغة العلم والتفكير، ولقد أرسى قواعد هذه اللغة علماء أجلاء تفرغوا للغوص في أعماقها من أجل الحفاظ عليها، ورفع صرحها، سواء أكانوا من الأمة العربية أم من الأمم الأخرى، ومن بين هؤلاء العلماء غير العرب، العلامة الفذ أبو الفتح عثمان بن جني. وسوف نلقي الضوء على جانب 
Mohamed Aziz Abdelmaksoud Sayed Ahmed, Ragab Ibrahim Ahmed Awad, Elsayed Mohamed Salem Alawadi

من جوانب إسهامات ابن جني في علم العربية، ألا وهو إسهامه في علمي العروض والقافية؛ لذا جاء عنوان البحث:" إسهامات ابن جني في علمي العروض والقافية." دأب الدارسون لابن جني أن يُعنوا بالدراسات اللغوية عنده سواء اكانت نهوية أم صرفية أم صوتية ام دلالية، وكذلك جهوده في علم القراءات، وغير ذلك، وقلما نجد أحدا عُني بدراسة ابن جني من حيث إسهاماته في علمي العروض والقافية؛ لذا كان البحث مهما من هذه الناحية؛ حيث يلقي الضوء على إسهامات ابن جني في هذا المجال، مع إبراز أهم ملامح منهجه

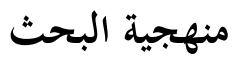

إن المنهج المتبع في هذا البحث قائم على المنهج الوصفي و التحليلي؛ حيث يصف حياة ابن جني، وآثاره، وما قدمه من إسهامات في علمي العروض والقافية، ويحلل هذه الجهود مع إبراز أهم ملامح منهجه فيها.

وسوف يعتمد الباحث في إسهامات ابن جني في علمي العروض والقافية على مصنفي ابن جني نفسه في هذين العلمين، وهما:

هتاب العروض، صنعة أبي عثمان بن جني النحوي رمه الله، وحقق هذا الكتاب كل من:

1- - الدكتور أحمد فوزي الهيب، الكويت، الطبعة الثانية، دار القلم للنشر والتوزيع، 1409

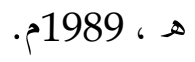

2- الأستاذ الدكتور حسني عبد الجليل يوسف، الطبعة الثانية، دار السلام للطباعة والنشر والتوزيع والترجمة، القاهرة، مصر 1431هـ ، 2010م. مختصر القوافي، تأليف أبي الفتح عثمان بن جني، 
Mohamed Aziz Abdelmaksoud Sayed Ahmed, Ragab Ibrahim Ahmed Awad, Elsayed Mohamed Salem Alawadi

تحقيق الدكتور حسن شاذلي فرهود، الطبعة الأولى، دار التراث،القاهرة 1395هـ، 1975م.

\section{نتائج الدراسة وتحليلها ابن جني حياته وآثاره.}

هو أبو الفتح عثمان بن جنبّي - وجني: بكسر الجيم وتشديد النون، وبعدها ياء - الموصلي

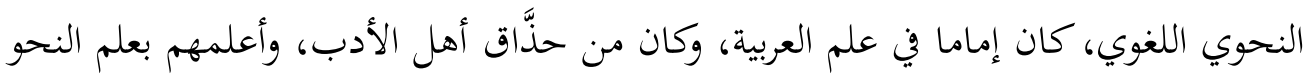
والتصريف، وصاحب التصانيف، وأبوه جِنّي مملوك مملوك روميّ لسليمان بن فهد ابن أحمد

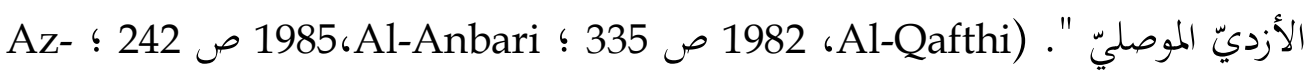
1983 Nisamburi ؛ Zarkali

وقيل "هو القطب في لسان العرب، وإليه انتهت الرياسة في الأدب"Nisamburi 1983) ص 137). وقال عنه صاحب الشذرات:" وله أشعار حسنة، ويقال :إنه أعور، وأخذ عن أبي علي الفارسي، ولازمه" (Al-Hanbali 1986). وقال عنه صاحب نزهة الألباء:" ولم يكن في

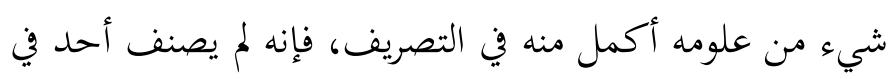
التصريف، ولا تكلم فيه أحسن ولا أدق كلاما منه " (Al-Anbari 1985).

كانت ولادة ابن جني قبل الثلاثين والثلثمائة بالموصل - Ibn Khalkan, 1975 ; Al Hanbali 1986; Al-Anbari 1985) ويشير محقق الخصائص إلى سنة ميلاده في قوله: ويقول من ترجم له: إنه ولد قبل الثلاثين والثلاثمائة من الهجرة، ولا يعينون مولده بعد هذا.ويقول

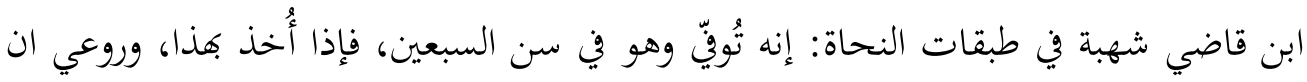
وفاته كانت في سنة 392 فإن ولادته تكون في سنة 322 أو سنة 321"(Ibn Jinni, 1952). 
Mohamed Aziz Abdelmaksoud Sayed Ahmed, Ragab Ibrahim Ahmed Awad, Elsayed Mohamed Salem Alawadi

يقول محمد علي النجار محقق الخصائص:" ولا تذكر لنا المراجع التي بأيدينا شيئا عن أبيه

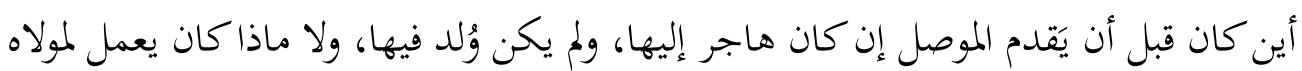

.(Ibn Jinni, 1952)

أبناؤه:

كان لابن جني من الولد علي وعال وعلاء، وكلهم أدباء فضلاء قد خرجهم والدهم،

وحسن خطوطهم، فهم

معدودون في الصحيحي الضبط وحسني الخط. (Ibn Jinni)، Al-Samra'i 5 1974 صنميم

(25 1969

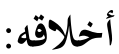

كان ابن جني رجل جدّ، وامرأ صدق في قوله وفعله، فلم يؤثر عنه ما أثر عن أمثاله من

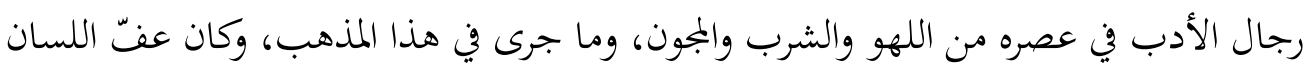

والقلم، يتجنّب الألفاظ المنْدِبة للجبين، والعُور من الكلم في تصنيفاته

شيوخه:

أخذ ابن جني عن كثير من رواة اللغة والأدب، ومن هؤلاء:

1 - أحمد بن محمد الموصلي.

يقول النجار:" إن ابن جني أخذ النحو في شبيته عن أحمد بن محمد

الموصلي" (Ibn Jinni)، لمول 1952 ص 14).

2- - م أبو علي الفارسي:

يقول صاحب نزهة الألباء :" وأخذ عن أبي علي الفارسي، وصحبه أربعين سنة "

245 (Al-Anbari)

ويقول النجار :" وبحمع الروايات على أن أبا الفتح صحب أبا علي بعد سنة 337،

ولازمه في السفر والحضر، وأخذ عنه، وصنف كتبه في حياة أستاذه، فاستجادها، 
Mohamed Aziz Abdelmaksoud Sayed Ahmed, Ragab Ibrahim Ahmed Awad, Elsayed Mohamed Salem Alawadi

ووقعت عنده موقع القبول، وهو كثير الاعتزاز بأبي علي، كثير الرواية عنه في كتبه، وهو يثني عليه الثناء الجمم"(Ibn Jinni، 1952 ص 19). 3- - مأبو الفرج الأصفهاني

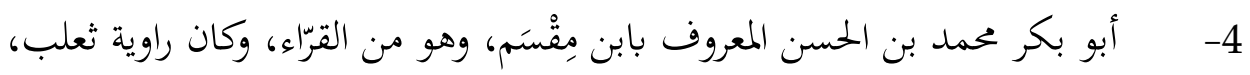
ووفاته 354 أو 355 هـ (Ibn Jinni، بن بن 1952 ص 14-15)

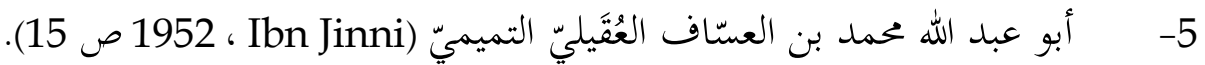

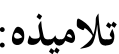

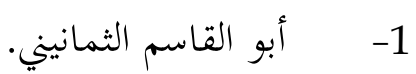
2- - مأبو أحمد عبد السلام البصري. 3- أبو الحسن علي بن عبيد الله الليق

توفي يوم الجمعة لليلتين بقيتا من صفر سنة اثنتين وتسعين وثلثمائة، رحمه الله، ببغداد 2002 Az-Zarkali 246 1975 ص Ibn Khalkan) 1985 ، Al-Anbari 3/248؛ ص 4/204؛ Al-Hanbali (4/2) (1986 198 ص 4/495)

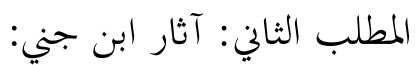
أهم مصنفاته الخصائص، سر صناعة الإعراب، المنصف في شرح نصريف أبي عثمان المازين،

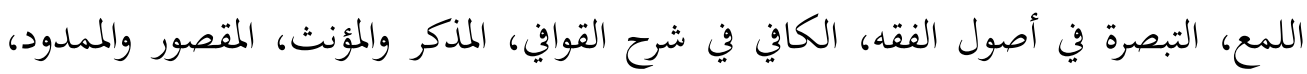
التذكرة الأصبهانية، التلقين في النحو، التعاقب، التمام في شرح شعر الهذليين، مختصر في العروض، يختصر في القوافي، التمام في شعر الهذليين، المسائل الخاطريات (Ibn Khalkan، 1975 ص 3/248؛ Al-Hanbali ، 1986 ص Q/4/494) و النشر وقيل الصبر (Aafthi، 1982 ص 2/337)، وهو شرح ديوان المتبي، وكان المتبي يقول:"ابن جني أعرف بشعري مني".Al (4/494 Hanbali 
Mohamed Aziz Abdelmaksoud Sayed Ahmed, Ragab Ibrahim Ahmed Awad, Elsayed Mohamed Salem Alawadi

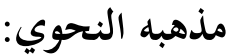

يقول الدكتور فرهود: "وكشيخه أبي علي الفارسي لم يكن ابن جني مقلدا غيره من أئمة البصرة أو الكوفة، وإنما كان صاحب مذهب مستقل انفرد به رغم انتمائه إلى مدرسة البصرة، فإلى جانب آرائه التي يشترك فيها مع البصريين، كانت له آراء انفرد بها عنهم وآراء أخرى انحاز فيها إلى جانب الكوفيين من غير تعصب أو هوى" (Ibn Jinni، 1975 ص 3). ومما يدل على أن ابن جني كانت نزعته بصرية أنه كان يشير إليهم في مصنفاته بقوله " أصحابنا

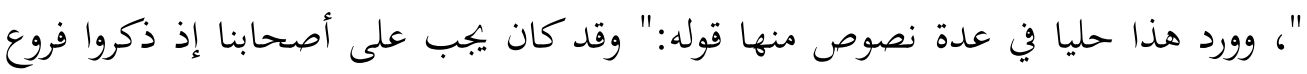
الحروف، نحو ألف الإمالة، وألف التفخيم، وهمزة بين بين، أن يذكروا أيضا الياء في نهو: قيل

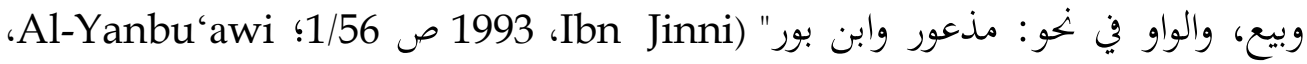

\section{إسهامات ابن جني في علم العروض التعريف بكتاب العروض لابن جني:}

نسبة الكتاب لابن جني كتاب العروض لابن جني كما رأينا من خلال ذكر مصنفاته من قبل أن من ترجم له أثبت نسبة مختصر في العروض لابن جني، وهذا المختصر طبع باسم " كتاب العروض"، وقد حققه كل من:

1- الأستاذ الدكتور حسني عبد الجليل يوسف، الطبعة الثانية، دار السلام للطباعة والنشر والتوزيع والترجمة، القاهرة، مصر 1431هـ ، 2010م

2- - الدكتور أحمد فوزي الهيب، الكويت، الطبعة الثانية، دار القلم للنشر والتوزيع،

$$
\text { منهج ابن جني في كتابه: } 1409 \text { هـ ، 1989م. }
$$

بدأ ابن جني كتابه ببيان أهمية علم العروض، ومفهوم الشعر، وفي هذا يقول في مقدمة كتابه:" اعلم أن العروض ميزان شعر العرب، وبه يُعرف صحيحه من مكسوره، فما وافق أشعار 
Mohamed Aziz Abdelmaksoud Sayed Ahmed, Ragab Ibrahim Ahmed Awad, Elsayed Mohamed Salem Alawadi

العرب في عدد الحروف: الساكن والمتحرك - سُمّي شعرا، وما خالفها فيما ذكرناه فليس شعرا، 1989 Ibn Jinni)." وإن قام ذلك وزنا في طباع أحد لم يُجْنَل به حتى يكون على ما ذكرناه

$$
\begin{aligned}
& \text { عرف ابن جني في مقدمته بعض المصطلحات العروضية الأولية، وهي: } \\
& \text { 1. السبب: ذكر أنه على ضربين: } \\
& \text { الأول: السبب الخفيف ( حرف متحرك وبعده حرف ساكن )، نهو: هَلْ. } \\
& \text { الثاني السبب الثقيل ( حرفان متحركان )، نحو: لَكَّ. }
\end{aligned}
$$

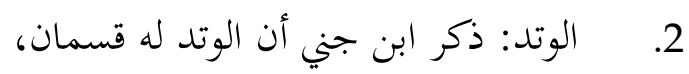

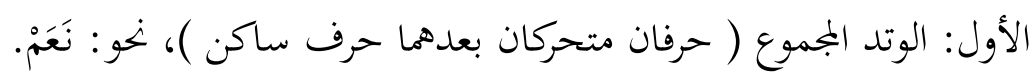

$$
\begin{aligned}
& \text { الثاني: الوتد المفروق ( حرفان متحركان بينهما حرف ساكن )، نحو : كَّفَّ. } \\
& \text { 3. الفاصلة: أشار ابن جني إلى أن الفاصلة لها نوعان: }
\end{aligned}
$$

الأول: الفاصلة الصغيرة: ( ثلاثة أحرف متحركة بعدها حرف ساكن )، نحو : خَرَجَتْ.

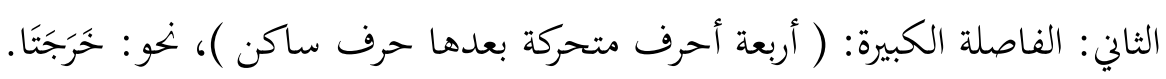
كيفية تقطيع الحروف: .4

رأى ابن جني أن تقطيع الحروف وهجاءه مبني على اللفظ، لا على الخط، فما وجد

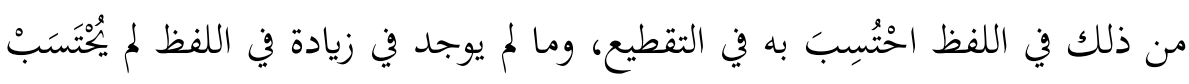

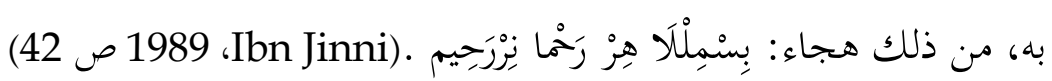

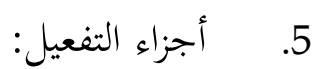

$$
\text { ذكر ابن جني أن أجزاء التفعيل ثمانية (Ibn Jinni، } 1989 \text { ص 41) : }
$$

ستة منها سباعية، وهي : مفاعيلن، فاعلاتن، مستفعلن، مفاعلتن، متفاعلن، مفعولاتُ واثنان منها خماسيتان، وهما: فعولن، فاعلن.

$$
\text { 6. مفهوم العروض والضرب: }
$$

عرف ابن جني عروض البيت بأنه آخر جزء من مصراعه الأول، وضربه بأنه آخر جزء من مصراعه الثاني. 
Mohamed Aziz Abdelmaksoud Sayed Ahmed, Ragab Ibrahim Ahmed Awad, Elsayed Mohamed Salem Alawadi

ثم بين أن أشعار العرب تنقسم إلى ثلاثة وستين ضربا، وأربع وثلاثين عروضا (Ibn Jinni،

(41 1989

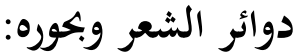

نظر المتقدمون في الشعر العربي فاستطاعوا أن يُرجعوه إلى خمسة عشر وزنا، أو ستة عشر على خلاف بينهم في الوزن السادس عشر، فالخليل بن أحمد الفراهيدي البصري واضع علم العروض، وأول من تكلم فيه لم يثبت عنده هذا الوزن، ولم يصح في روايته ما جاء من الشعري بن

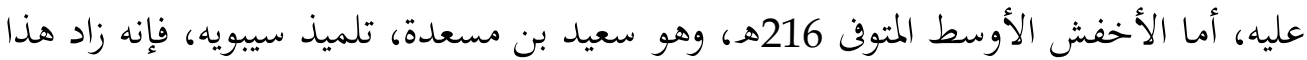

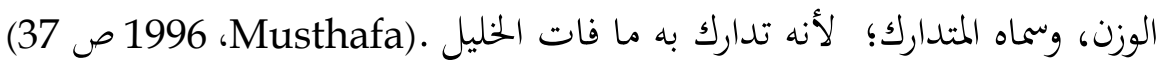
وابن جني ينهج منهج شيخه الخليل في اختياره عدد بحور الشعر خمسة عشر بحرا، وأشار إلى أنها تأتي على خمس دوائر على النحو الآتي (Musthafa، 1996 ص 37) الطول والمديد والبسيط - دائرة. الوافر والكامل - دائرة. والهزج والرجز والرمل - دائرة. والسريع والمنسرح والخفيف والمضارع والمقتضب والمجتث - دائرة.

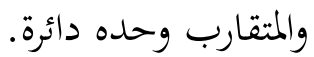

سار ابن جني في كتابه على هدى الخليل بن أحمد ، فاتفق معه على عدد البحور الخمسة عشر، وعلى استبعاد البحر السادس عشر وهو المتدارك الذي أشار إليه الأخفش الأوسط، وعلى عدد الدوائر العروضية، وعلى غير ذلك من الأمور (Ibn Jinni، 1989 ص 18)

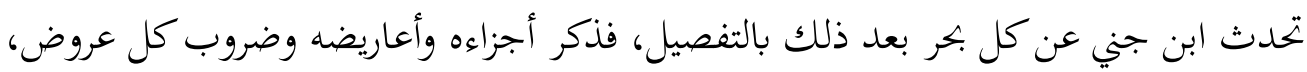

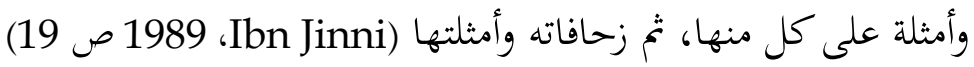


Mohamed Aziz Abdelmaksoud Sayed Ahmed, Ragab Ibrahim Ahmed Awad, Elsayed Mohamed Salem Alawadi

\section{نماذج من إسهامات ابن جني في مختصره}

وينفرد هذا المختصر بميزتين، كما ذكرها الدكتور حسني عبد الجليل Ibn Jinni)، 1989

(3)

الأولى: الكتابة العروضية المقطعية، أي: تلك التي تبدأ بمتحرك، وتنتهي بساكن، وهو نمط من الكتابة لم يلتزم به من سبقه، أو من عاصره، أو من جاء بعده، فهي طريقة موضوعية تُيَّرَ كثيرا على الدارس فهم المكتوب، وإنجازه.

الثانية: انفردت بها مخطوطة دار الكتب المصرية؛ حيث التزم فيها الناسخ بالقواعد الصحيحة للقراءة العربية من إدغام وإقلاب في الكتابة العروضية، أو لِنقل: ألزم ابن جني الناسخ بذلك،

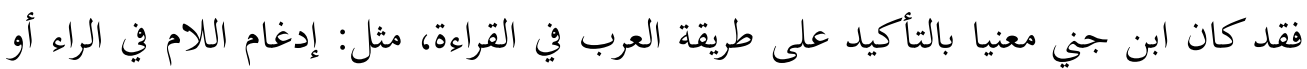
النون، وإقلاب النون ميما قبل الباء، وقبل الميم. شواهد على الكتابة العروضية عند ابن جني: أشار الدكتور عبد الجليل إلى طريقة الكتابة العروضية عند ابن ؛ حيث ذيثر ذئر بعض النماذج من إحدى مخطوطات الكتاب، ومنها: أولا: إقلاب النون الساكنة ميما قبل الباء (Ibn Jinni، 1989 ص 14) يقول عدي بن زيد:

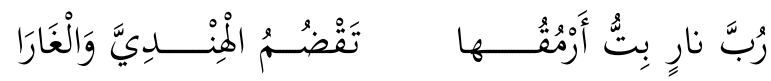

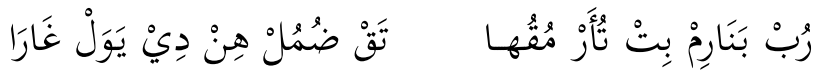
الشاهد: نارم بت؛ حيث قلب النون الناشئة من التنوين ميما قبل الباء. ثانيا: إدغام النون الساكنة في الميم (Ibn Jinni، 1989 ص 23)

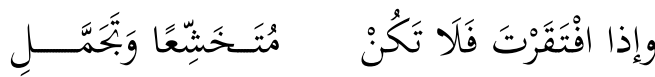

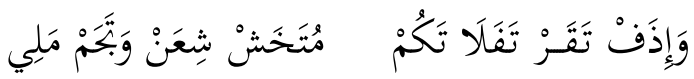

الشاهد: تَكُمْ مُتَخَشْ ؛ حيث قلب نون التنوين الساكنة ميما، وأدغمها في الميم التي بعدها. ثالثا: إدغام النون في اللام (Ibn Jinni، 1989 ص 25) 
Mohamed Aziz Abdelmaksoud Sayed Ahmed, Ragab Ibrahim Ahmed Awad, Elsayed Mohamed Salem Alawadi

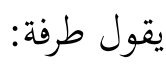

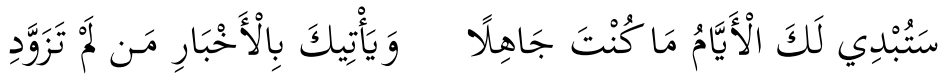

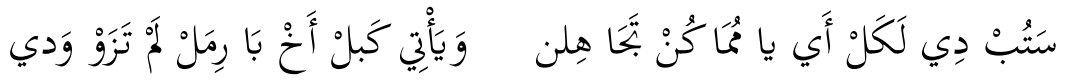

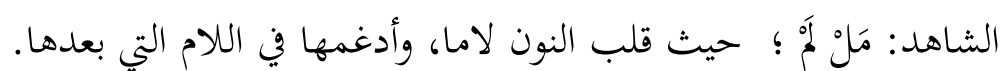

\section{إسهامات ابن جني في علم القافية}

علم القافية هو علم ضيق المجال بطبيعته؛ لذا من تحدث فيه بعد الخليل والأخفش لم

يضف إليه كثيرا سوى تحرير مصطلحه، والاختلاف في بعض عيوب القافية، ونخو ذلك (-Al 1874 ، Akhfasy في نسبته إليه(Al-Hanbali 1986; Al-Irbili, n.d.) ، Ibn Khalkan) (Al 1986 ص 4/494؛ ترك Al-Hanbali اسم كتابه، فقال:" قال أبو الفتح عثمان بن جني رحمه الله تعالى: هذا علم القوافي غختصر" (Ibn Jinni) بعون الله، وحسن تأييده، والصلاة على سيدنا محمد وآله وصحبه"' (Ibn Jinni، 1975).

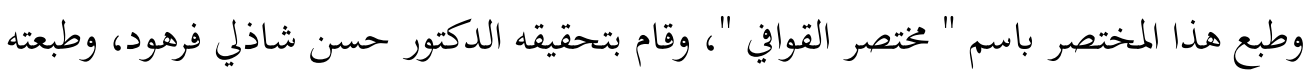
دار التراث، والنسخة التي بين أيدينا هي من الطبعة الأولى (شعبان 1395ه، أغسطس 1975م).

\section{منهج ابن جني في مختصر القوافي:}

تناول ابن جني في مختصر القوافي خمسة أشياء رئيسة، وبتلّت ملامح منهجه فيما يأتي: أولا: في مفهوم القافية:

أشار ابن جني إلى تعريف القافية، وذكر رأيين للخليل والأخفش دون أن يبدي رأيه.

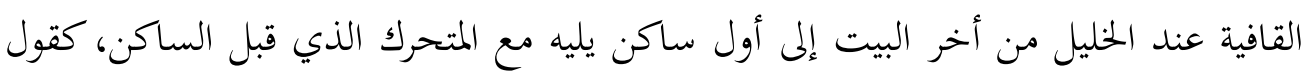
الشاعر:

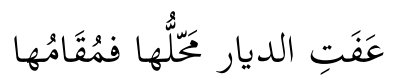


Mohamed Aziz Abdelmaksoud Sayed Ahmed, Ragab Ibrahim Ahmed Awad, Elsayed Mohamed Salem Alawadi

فالقافية عنده من القاف إلى آخره البيت، وهي عند أبي الحسن آخر كلمة في البيت أجمع (bn

19 1975 ، Jinni

$$
\begin{aligned}
& \text { ثانيا: فج فهج من قبله في الأشياء المتبقية من خلال ثلاثة أشياء : } \\
& \text { 1-ذكر المصطلح. 2- بيان المقصود به. 3- شاهد من الشعر. }
\end{aligned}
$$

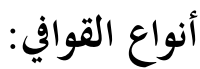

$$
\text { أنواع القافية عنده (Ibn Jinni، } 1989 \text { ص 19-20) : }
$$

أولا : المتكاوس وهو كل قافية كان فيها أربعة أحرف متحركة بين ساكنين. O///O يقول

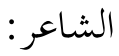

\section{قَدْ جَبَرَ الدِّينَ الْإِلَهُ فَجَبَرْ}

ثانيا : المتراكب وهو كل قافية كان فيها ثلاثة أحرف متحركات بين ساكنين. O//O يقول الشاعر:

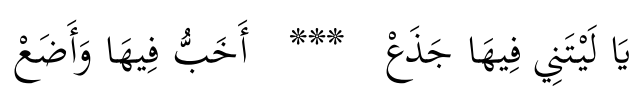

ثالثا: المتدارك وهو كل قافية وقع فيها متحركان بين ساكنين. O//O ، يقول الشاعر:

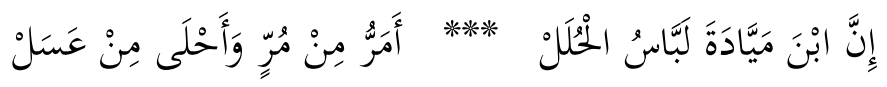

رابعا : المتواتر وهو كل قافية وقع فيها متحرك بين ساكنين. O/O ، يقول الشاعر: تَغَمَّْْنِي بنُصْحِكَكَ فِي انْفِرادِي

خامسا : المترادف وهو كل قافية توالى فيها ساكنان.OO يقول الشاعر:

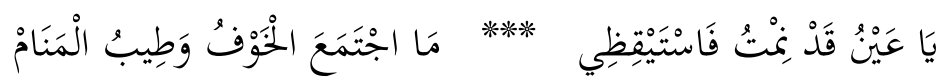

$$
\text { الحروف والحركات: المرات }
$$

$$
\begin{aligned}
& \text { يقول ابن جني في بيان الحروف والحركات :"ويعرض في القافية من الحروف والحركات } \\
& \text { المسميات المراعيات ستة أحرف وست حركات" (Ibn Jinni، } 1989 \text { ص 20). }
\end{aligned}
$$


Mohamed Aziz Abdelmaksoud Sayed Ahmed, Ragab Ibrahim Ahmed Awad, Elsayed Mohamed Salem Alawadi

\section{الحروف:}

بيّن ابن جني أقسام الحروف في قوله " فالحروف: الروي والوصل والحُروجرج والرّدِف

$$
\text { والتأسيس والدَّخيل". (Ibn Jinni)، } 1989 \text { ص 21). }
$$

الروي: هو الحرف الذي تبنى عليه القصيدة، ويأي في آخر القصيدة، ويتكرر في أبياتا، وإليه ثُنسب القصيدة، فيقال: قصيدة رائية، أو لامية، أو ميمية، أو نونية.

الوصل: يكون بأربعة أحرف الألف والياء والواو ( السواكن ) والهاء ساكنة ومتحركة. وهذا

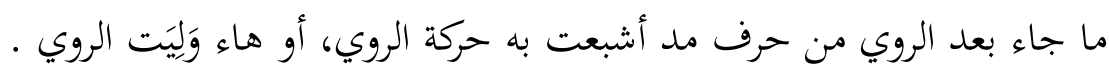
الخروج: بثلاثة أحرف، وهي: الألف والياء والواو يتبعن هاء الضمير إذا كانت وصلا؛ أي أن حرف المد يلي هاء الوصل المتحركة .

الردف: يكون بثلاثة أحرف وهي: الألف والياء والواو يلين حرف الروي سواكن من قبله ؛

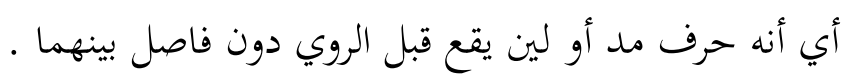

التأسيس: هو ألف قبل حرف الروي بحرف، وهي معه من كلمة واحدة؛ أي أنه ألف بينها وبين الروي حرف واحد متحرك .

الدخيل: هو الحرف الذي بين التأسيس والروي؛ أي أنه الحرف المتحرك الفاصل بين الروي وألف التأسيس.

أشار ابن جني إلى أن الحركات ست، وهي المجرى والنفاذ والحَذْو والرَُُّوّوالإشباعُ والتوجيه. عيوب القافية (Ibn Jinni، 1975 ص 28-29) :

$$
\text { الجلجرى: هو حركة الروي. النفاذ: هو حركة هاء الوصل الواقعة بعد الرَّوي. }
$$


Mohamed Aziz Abdelmaksoud Sayed Ahmed, Ragab Ibrahim Ahmed Awad, Elsayed Mohamed Salem Alawadi

$$
\begin{aligned}
& \text { الرَّسُ: الفتحة قبل ألف التأسيس؛ أي هو حركة ما قبل ألف التأسيس. } \\
& \text { الإشباعُ: هو حركة حرف الدخيل إذا كان الروي مطلقا. } \\
& \text { التوجيه: هو حركة ما قبل الرّوي المقيّد، أي الساكن }
\end{aligned}
$$

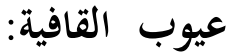

أشار ابن جني إلى عيوب القافية، وهي الإكفاء والإقواء والإيطاء والسناد (Ibn Jinni،

الإكفاء : هو اختلاف الروي؛ وذلك إذا كانت الحروف متقاربة المخارج. مثال: يقول الشاعر:

$$
\begin{aligned}
& \text { إِذَا رَكْبْتُ فَاجْعَلَالِي وَسَطا } \\
& \text { إِيّ كببيِرٌ لَا أُطيقُ الْعُسنَّدَا }
\end{aligned}
$$$$
\text { ويلاحظ أن الشاعر جمع بين الطاء والدال؛ لقرب مخرجهما. }
$$

الإقواء: هو اختلاف حركة الروي في قصيدة واحدة، وهو أن يجيء بيتُ مرفوعا وآخر مجرورا.

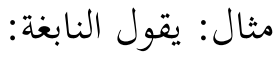

أَمِنْ آلِ مَيَّة رَائِحِ أَوْ مُغْغَدِي

زَعَمَ الْبَوَارِحَ أنَّ رِحْلَتَنَا غَدًَا

ونلحظ أن كلمة " مُزَوَّدٍ " جاءت مجرورة، فهي مضاف إليه، وكلمة " الََْسَْوُد " جاءت مرفوعة، رِ فهي صفة.

الإيطاء : هو أن تجمع في شعر واحد بين كلمتين بلفظ واحد، ومعنى واحد ؛ أي هو إعادة

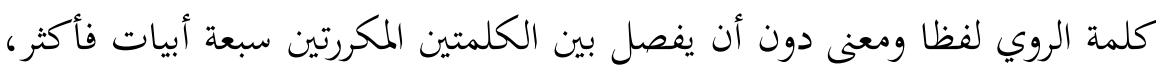

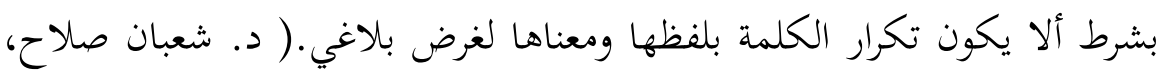
2005، ص 301 ).مثال: يقول الشاعر: 
Mohamed Aziz Abdelmaksoud Sayed Ahmed, Ragab Ibrahim Ahmed Awad, Elsayed Mohamed Salem Alawadi

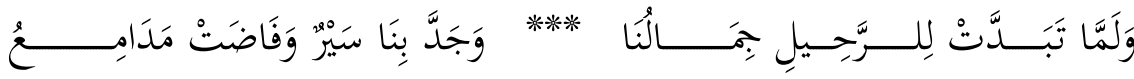

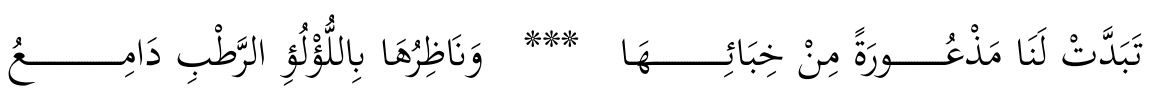

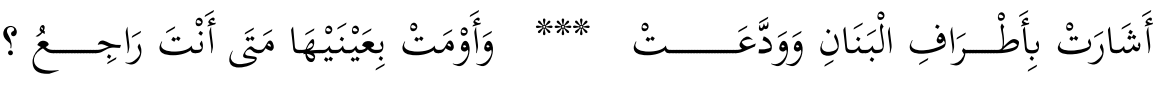

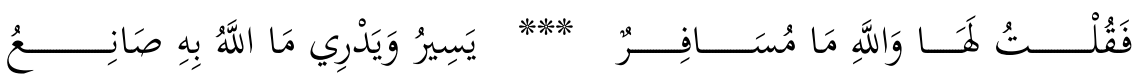

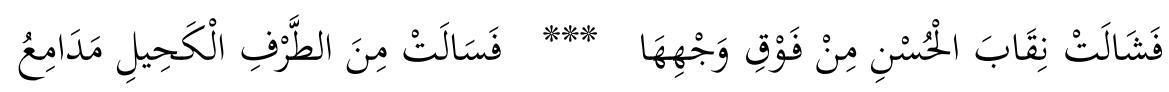

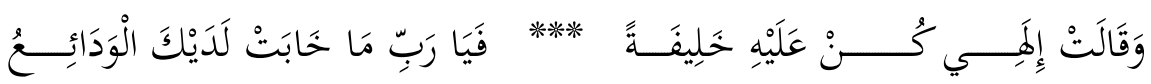

ونلحظ أن الشاعر ذكر كلمة " مدامع " في البيت الأول، ثم أعاد ذكرها في البيت الخامس، وهذا يعد إيطاء.

السناد: هو اختلاف ما يراعى قبل الروي من حروف وحركات، مثل القافية المؤسسة مع القافية المجردة. مثال: يقول الشاعر: الشئل

فَلَمْ أَرَ شَيْيًَا كَانَ أَحْسَـــنَ مَنْظَــرًا

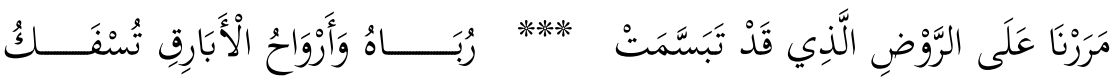
ونلحظ هنا أن البيت الأول فيه ألف تأسيس، ولكن البيت الثاني خلا منها.

الخلاصة

بعد أن طفنا سريعا مع ابن جني في علمي العروض والقافية يمكن استنتاج بعض النتائج

أولا: أن ابن جني في كتابه العروض سار على هدى الخليل بن أحمد ، فاتفق معه على عدد

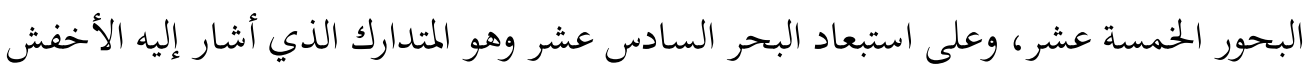
الأوسط، وعلى عدد الدوائر العروضية، وعلى غير ذلك من الأمور. 
Mohamed Aziz Abdelmaksoud Sayed Ahmed, Ragab Ibrahim Ahmed Awad, Elsayed Mohamed Salem Alawadi

ثانيا: أن ابن جني أبدع في الكتابة العروضية المقطعية، أي: تلك التي تبدأ بمتحرك، وتنتهي

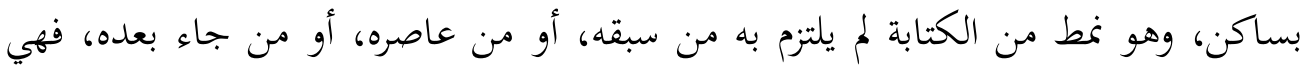
طريقة موضوعية تُيَّر كثيرا على الدارس فهم المكتوب، وإنجازه.

ثالثا: أن الناسخ التزم بالقواعد الصحيحة للقراءة العربية من إدغام وإقلاب في الكتابة العروضية،

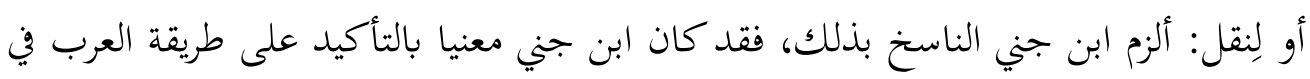
القراءة، مثل: إدغام اللام في الراء أو النون، وإقلاب النون ميما قبل الباء، وقبل الميم.

رابعا: أن ابن جني سار في مختصره في علم القافية على فه من سبقه، وتناول خمسة أشياء في مختصره، وهي نفس ما ذكره القدامى: مفهوم القافية - أنواع القافية - حروف القافية - حركات

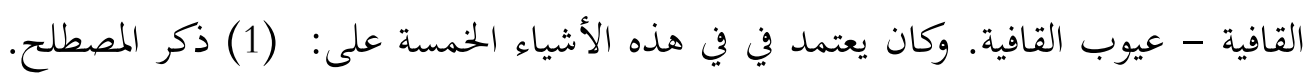
(2) شرح المصطلح. (3) ذكر شاهد شعري عليه.

\section{المصادر والمراجع}

Al-Akhfasy, M. 1974. Kitab Al-Qowafi. Edited by Ahmad Ratib AnNufakh. 1st ed. Beirut : Dar Al-Amanah.

Al-Anbari, M. 1985. Nazhah Al-Alba Fi Thabaqat Al-Adibba. Edited by Ibrahim As-Samirai. 3rd ed. Urdun: Maktabah al-Manar.

Al-Fatali, H. A. H. (2013). Ushul Al-Tafkir Al-Nahwi Inda Ibn Jinni. Majalla Kulliyyah Al-Tarbiyah Al-Asasiyah, 14, 535-556.

Al-Hanbali, A.A. 1986. Sadzarat Adz-Dzahb Fi Akbar Min Dzhab. Edited by Mahmud Al-Arnauth. 1st ed. Damascus: Dar Ibn Katsir.

Al-Samra'i, F. S. (1969). Ibn Jinni Al-Nahwi. Baghdad: Dar Al-Nazir. Al-Qafthi, J. 1982. Inbah Ar-Ruwat 'ala Anbah An-Nuhat. Edited by Muhommad Abu Fadal Ibrahim. 1st ed. Cairo: Dar Al-Fikr AlArabi. 
Mohamed Aziz Abdelmaksoud Sayed Ahmed, Ragab Ibrahim Ahmed Awad, Elsayed Mohamed Salem Alawadi

Al-Yanbu'awi, G. A (1991). Juhud Ibn Jinni fi Al-Syarf Wa Taqwimia fi Dhoui Ilmi Lughah Al-Hadist. Umm Al-Qura.

Az-Zarkali, K. 2002. Al-'Alam Qamus Tarajim. 5th ed. Beirut-Lebanon: Darul Ilm lil malayin.

Halim, R. (2010). Al-Lughah Al-Syi'riyah Inda Ibn Jinni Qiroat Tahliliyah fi Ta'silihi Lidharurati Al-Syi'riyah. Qiraat, 2(1), 3053015 .

Hasan, S. K. (2019). Al-Taqrib Al-Sauthi Inda Ibn Jinni. Adab Basrah, 89, 76-92. https://doi.org/10.33762/1162-000-089-003

Ibn Jinni. 1952. Al-Khasais. Edited by Muhammad Ali An-Najar. Mesir: Dar Kutub al-Mishriyah.

- - . 1975. Mukhtasar Al-Qowafi. Edited by Hasan Syadzil Farhud. 2nd ed. Cairo: Dar At-Turats.

- - - 1989. Kitab Al-'Arud. Edited by Ahmad Fauzi Al-Haib. 2nd ed. Kuwait: Dar Qolam.

- - - 1993. Sirr Sina'ah al-'Irab. Edited by Hasan Handawi. 1st ed. Damascus: Dar Al-Qalam.

Ibn Khalkan. 1972. Wafayat Al-'Ayan Wa Anba Abna Az-Zaman. Edited by Ihsan Abbas. Beirut: Dar Shadir.

Musthafa, M. 1996. Uhdi Sabil Ila 'Ilm Kholil Al-'Arud Wal Qofiyah. Edited by Said Muhammad Al-Liham. 1st ed. Beirut-Lebanon: 'Alim alKutub.

Nisamburi, A. 1983. Yatimah Ad-Dahr Fi Mahasin Ahlil Ashr. Edited by Mufid Muhammad Qamihah. 1st ed. Beirut-Lebanon: Dar Kutub al-Ilmiyah. 
Mohamed Aziz Abdelmaksoud Sayed Ahmed, Ragab Ibrahim Ahmed Awad, Elsayed Mohamed Salem Alawadi

Raheem, J. H. A. (1983). Mauqufi Ibn Jinni Min Al-Dharurat. Al-Lisan Al-Arabi, 21, 37-45.

Solah, S. (2005). Musiqo Al-Syi'ir Baina Al-Ittiba' Wa Al-Ibtida'. Cairo: Dar Ghareeb.

Sulaeman, A.-S. M. A. (2014). Ma'alim al-Talaqi Baina Ibn Jinni wa AlIttijahat Al-Lughawiyah Al-Haditsah. In M. Basheer, Thajudee-AS, \& Noushad (Eds.), Arabic Language and Literature: A Contemporary View (pp. 145-161). University of Kerala.

Wardia, Z. (2011). Rukyat Ibn Jinni Li Al-Syi'ir [Tizi Ouzou University]. http:/ / mohamedrabeea.net/library/pdf/3207bec4-47e3-4b9c9c99-ca551f2d6bbb.pdf 